\title{
Hospitals of the Mexican Institute of Social Security in the face of September 2017 earthquakes. Analysis from the perspective of the Safe Hospital Program
}

\author{
Felipe Cruz-Vega, Sandra Elizondo-Argueta, Juan Carlos Sánchez-Echeverría and \\ Jorge Loría-Castellanos \\ Instituto Mexicano del Seguro Social, Medical Benefits Management, Special Health Projects Division, Ciudad de México, Mexico
}

\begin{abstract}
Introduction: The function of hospitals during major emergency or disaster is vital. Their response capacity depends on their geographic location, adequate organization, structural safety and safety of non-structural elements. After September 2017 earthquakes, self-assessment and Safe Hospital Program assessment results were compared in disabled hospitals belonging to the Mexican Institute of Social Security. Objective: To compare the Hospital Safety Index (HIS) with self-assessments carried out by the units. Method: HIS and the Pan-American Health Organization/World Health Organization checklist were used. The comparison was carried out in 3 hospitals that were disabled after September 2017 earthquakes. Results: Variability was observed in HIS, which revealed self-assessment biases: no hospital obtained a HIS score lower than 0.35, although all 3 were disabled in the immediate phase after the seismic events. Conclusions: Result variability depends on who applies the instrument. Quick HIS assessment provides an immediate idea of the probability for a hospital to continue functioning in case of disaster and allows determining mitigation actions to increase health facilities' resilience and safety.
\end{abstract}

KEY WORDS: Resilience. Safe hospital, Earthquake

\section{Introduction}

The role of hospitals during an emergency or disaster is vital. Their response for the care of victims and avoidance of life losses will depend not only on their organization, but also on that their facilities are able to withstand such contingency, i.e., of being safe hospitals. ${ }^{1}$

Keeping a hospital safe depends on four essential factors: its geographical location, its organization level, safety of the building and safety of non-structural architectural elements (vital lines, furniture and equipment).

According to the Pan American Health Organization and World Health Organization (PAHO/WHO) definition, a safe hospital is "a health facility the services of which remain accessible and functioning at its maximum installed capacity and in the same infrastructure, immediately after a destructive phenomenon of natural origin", a concept that was implemented as a national risk-reduction policy by several countries, including Mexico, and that allows hospitals to have the minimum indispensable measures to protect life, investment and functioning since their planning.

To determine that a hospital is safe, a multidisciplinary team applies the PAHO/WHO checklist ${ }^{1}(\mathrm{CL})$, which is a reliable and low-cost quick assessment tool that provides an immediate idea of the probability for a health establishment to continue functioning in cases of disaster, without replacing more complex vulnerability studies, by obtaining the hospital safety index (HSI).

In this research, hospitals of the Mexican Institute of Social Security (IMSS - Instituto Mexicano del Seguro Social) that were damaged by the earthquakes of September 7 and 19, 2017 in Mexico and their HSI results are analyzed after two self-assessments and an evaluation of the Safe Hospital Program (PHS - Programa Hospital Seguro).
Correspondence: Jorge Loría-Castellanos E-mail: jloriac@ hotmail.com
Date of reception: 17-04-2018

Date of acceptance: 18-07-2018

DOI://dx.doi.org/10.24875/GMM.M18000192
Gac Med Mex. 2018;154:487-492

Contents available at PubMed www.gacetamedicademexico.com 
Table 1. Measures and schedule of actions with regard to the Hospital Safety Index results in hospitals of the Mexican Institute of Social Security

\begin{tabular}{lll}
\hline Category & Hospital Safety Index & Interpretation of results (necessary measures) \\
\hline A & 0.66 to 1 & $\begin{array}{l}\text { Urgent measures } \\
\text { Although the hospital is likely to continue operating in case of disaster, continuing with measures } \\
\text { to improve the response capacity and carrying out medium and long-term preventive measures is } \\
\text { recommended, in order to improve the safety level in the eventuality of disasters. }\end{array}$ \\
& $\begin{array}{l}\text { Short-term measures } \\
\text { B }\end{array}$ & $\begin{array}{l}\text { Necessary measures are required in the short term, as current safety levels of the facilities can } \\
\text { potentially put patients, staff and functioning at risk during and after a disaster. }\end{array}$ \\
C 0.36 to 0.65 & $\begin{array}{l}\text { Medium and long-term measures } \\
\text { Urgent and immediate measures are required, since the facilities' safety levels are insufficient to protect } \\
\text { the lives of patients and staff during and after a disaster. }\end{array}$ \\
\hline
\end{tabular}

\section{Background of Mexico's Safe Hospital Program}

Mexico's PHS has as its background in the International Conference on Disaster Mitigation in Health Facilities (1996), where recommendations and commitments to promote disaster mitigation strategies in health facilities were issued. ${ }^{2}$ Subsequently, the Safe Hospitals in Disasters strategy was included in the Hyogo Action framework $^{3}$ (2005) and ratified in the Sendai Framework ${ }^{4}$ (2015), whereby emphasis was made on the importance of damage and service interruption reduction, as well as on health facilities' resilience; resilience is understood as the capability a system, a community or a society exposed to a threat has to resist, absorb, adapt, transform and timely and efficiently recover from its effects, in particular through the preservation and restoration of its structures and basic functions through the management of risks, according to the United Nations Office for Disaster Risk Reduction.

In 2006, Mexico established the National Committee for Evaluation, Diagnosis and Certification of the Safe Hospital Program (CNEDCPHS - Comité Nacional de Evaluación, Diagnóstico y Certificación del Programa Hospital Seguro), directed by the Civil Protection National Coordination Agency (CNPC - Coordinación Nacional de Protección Civil) of the Ministry of the Interior, a governing entity for civilian protection that has the faculties to act from the legal field. CNEDCPHS is comprised by official representatives of public, private and social organizations, which allows a global and balanced vision, and is responsible for hospital evaluations within the PHS.

\section{Mexican Institute of Social Security and the Safe Hospital Program}

The Mexican Institute of Social Security is the largest social security institution in Latin America, which serves

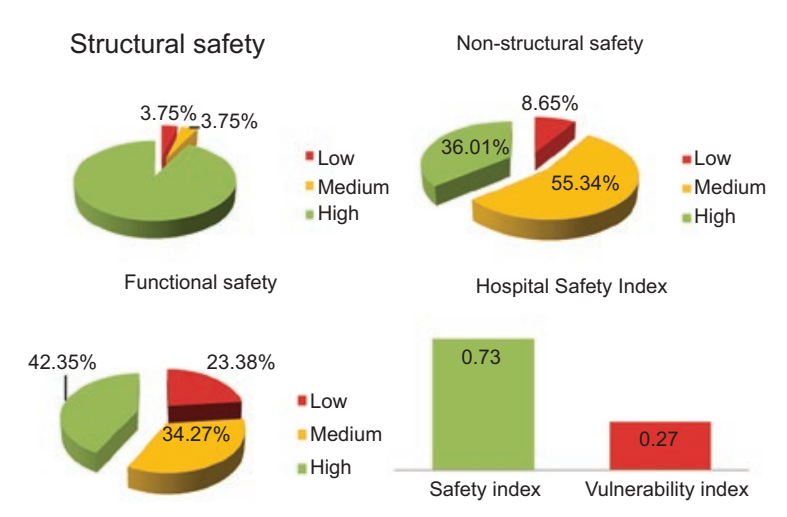

Figure 1. Hospital Safety Index graphic example.

medical units throughout the country, out of which 297 are secondary and tertiary care hospitals. ${ }^{5}$

A priority strategy in that institution after the 1985 earthquakes was to have "safe hospitals" available; one of the lessons learned was the need to evacuate 2300 patients from the hospitals that integrated the National Medical Center in Mexico City and that were disabled due to the damages in vital lines. After damage assessment, buildings (10 to 12-floor tall) were demolished and new buildings were built with foundations over 14 meters deep, no more than six-floor tall and with structural technology that incorporated energy dissipators. ${ }^{6}$ Following up on this strategy, in 1997, the Institute signed a technical collaboration agreement with $\mathrm{PAHO} / \mathrm{WHO}$ to develop a program for hospitals' evaluation and diagnosis and to implement measures to increase their safety and strengthen their infrastructure in situations of disaster. ${ }^{7}$

At the time of this report, CNEDCPHS had evaluated 151 hospitals of the Mexican Institute of Social Security using the PAHO/WHO CL; once the evaluation was made, the PAHO/WHO mathematical model was applied to determine the $\mathrm{HSI}{ }^{8}$ which classifies hospitals in categories $A, B$ and $C$, which prioritize intervention necessities for increasing hospital safety (Table 1 and Figure 1). Of the 
Table 2. Mexican Institute of Social Security hospitals with damages caused by September 2017 earthquakes

\begin{tabular}{|c|c|c|c|c|c|c|c|}
\hline Entity & $\begin{array}{l}\text { Hospitals per } \\
\text { entity }(n)\end{array}$ & $\begin{array}{l}\text { Hospital beds in } \\
\text { the entity (n) }\end{array}$ & $\begin{array}{l}\text { Hospitals with } \\
\text { damages }\end{array}$ & $\begin{array}{l}\text { Available beds in the } \\
\text { hospital (n) }\end{array}$ & $\begin{array}{c}\text { Disabled } \\
\text { hospital beds }(n)\end{array}$ & $\begin{array}{l}\text { Time to recover } \\
\text { functionality }\end{array}$ & $100 \%$ of \\
\hline \multirow[t]{2}{*}{ Puebla } & \multirow[t]{2}{*}{7} & \multirow[t]{2}{*}{728} & 415 & $\begin{array}{l}\text { HGR } 36 \text { "San } \\
\text { Alejandro" }\end{array}$ & 415 & \multicolumn{2}{|c|}{ Building of new hospital in } \\
\hline & & & 42 & HGZ 5 Metepec & 0 & 4 months & $\frac{c}{\delta}$ \\
\hline \multirow{3}{*}{$\begin{array}{l}\text { Mexico } \\
\text { city }\end{array}$} & \multirow[t]{3}{*}{15} & \multirow[t]{3}{*}{2674} & 272 & HGR 25 I. Zaragoza & 272 & 8 months & $\frac{5}{4}$ \\
\hline & & & 103 & Gineco-pediatría $3 \mathrm{~A}$ & 0 & 3 weeks & (2) \\
\hline & & & 205 & HGZ 32 Villa Coapa & 205 & 1 year & \\
\hline Morelos & 3 & 394 & 52 & HGZ/UMF 7 Cuautla & 52 & 1 year & $\frac{c}{n}$ \\
\hline \multirow{2}{*}{$\begin{array}{l}\text { State of } \\
\text { Mexico }\end{array}$} & \multirow[t]{2}{*}{17} & \multirow[t]{2}{*}{1838} & 149 & HGZ/UMF 68 Tulpetlac & 0 & 3 weeks & $\frac{0}{3}$ \\
\hline & & & 185 & $\begin{array}{l}\text { HGR } 196 \text { Fidel } \\
\text { Velázquez }\end{array}$ & 0 & 3 weeks & 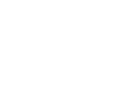 \\
\hline Total & 43 & 5634 & 1423 & 8 & 944 & & $\frac{\varsigma}{0}$ \\
\hline
\end{tabular}

HGR (Hospital General Regional) = Regional General Hospital, HGZ (Hospital General de Zona) = Zone General Hospital, HGZUMF (Hospital General de Zona con Unidad de Medicina Familiar) $=$ Zone General Hospital with Family Medicine Unit.

151 hospitals, 4 had been classified in category $C$, three due to vulnerability in non-structural and functional safety and one due to vulnerability in structural safety, which was shut down and demolished; hospitals with classification $A$ and $B$ showed vulnerability in non-structural safety, which has been mitigated with reinforcement actions, as well as vulnerability in functional organization, and courses for health care operative and managerial personnel were therefore implemented in hospital plans to face emergencies and disasters and undertake actions against different threats.

\section{September 2017 earthquakes}

Two earthquakes occurred in September 2017: on the $7^{\text {th }}$ at 23:49:18 hours, with a magnitude of 8.2 and epicenter $133 \mathrm{~km}$ southwest of Pijijiapan, Chiapas, which affected the states of Oaxaca and Chiapas; 9 and on the $19^{\text {th }}$ at 13:14:40 hours, with a magnitude of 7.1, epicenter $12 \mathrm{~km}$ southeast of Axochiapan, Morelos, which affected Morelos, Puebla, Mexico City and the State of Mexico. ${ }^{10}$

\section{Methods}

Information of the Mexican Institute of Social Security about hospitals that suffered damage secondary to the September 2017 earthquakes and the results of the CNEDCPHS evaluation and two self-assessments carried out as part of the internal routine actions of the Institute were analyzed.

\section{Results}

\section{Impact of the earthquakes on IMSS hospital infrastructure}

The zone affected by both earthquakes included six states of the country, no medical unit of the Institute did collapse, there were no deaths among the personnel, patients or visitors and only the September 19 earthquake caused damages in some hospital units.

As a result of the earthquakes, there were damages in 8 hospitals located in 4 entities of the country: Mexico City, the State of Mexico, Puebla and Morelos (Table 2), 4 with disabling damage ( 3 were shut down and one had a partial closure), which represented a 944-bed deficit (12\%) out of 5634 hospital beds in these entities. ${ }^{11}$

The main damages in the 4 units that were not disabled were associated with architectural elements: detachment of ceilings, separation in division walls, plasterwork cracks, broken glasses, detachment of coatings on building joints; patient care was not suspended and functioning to a $100 \%$ was achieved in a 3-week to 4-month period, since the units have plans for adapting areas and suspending non-priority services (operation continuity plan); one example was Hospital General de Zona 5 from Metepec, Puebla, where the damage disabled the operating rooms' area and two mobile surgical units were installed.

Hospital General Regional 25, with 272 beds, suffered damage to walls and finishes in the hospitalization area, 
Table 3. Results of assessments and self-assessments based on the checklist

\begin{tabular}{|c|c|c|c|c|c|c|}
\hline \multirow[t]{2}{*}{ Entity } & \multirow[t]{2}{*}{ Hospital } & \multirow{2}{*}{$\begin{array}{c}\text { Start of } \\
\text { operations }\end{array}$} & \multirow{2}{*}{$\begin{array}{l}\text { Assessment } \\
\text { date }\end{array}$} & \multicolumn{3}{|c|}{ Category/HSI } \\
\hline & & & & $\begin{array}{l}\text { CNEDCPHS } \\
\text { Assessment }\end{array}$ & $\begin{array}{c}\text { SIl-PC } 2012 \\
\text { Self-assessment }\end{array}$ & $\begin{array}{c}\text { CIRI } 2016 \\
\text { Self-assessment }\end{array}$ \\
\hline Mexico City & HGZ 32 Villa Coapa & 1976 & $\begin{array}{l}2007 \\
2014\end{array}$ & $\begin{array}{l}B(0.64) \\
B(0.59)\end{array}$ & $A(0.96)$ & $\mathrm{B}\left(\begin{array}{c}0.65) \\
\frac{E}{E} \\
E\end{array}\right)$ \\
\hline Morelos & HGZ/UMF 7 Cuautla & 1968 & 2014 & $A(0.73)$ & $A(0.79)$ & $\mathrm{B}(0.47)$ \\
\hline Puebla & HGR 36 "San Alejandro" & 1972 & 2007 & $B(0.62)$ & $A(0.73)$ & $B(0.56)$ \\
\hline
\end{tabular}

which was deemed to be disabled; rehabilitation was scheduled to take 8 months and it continues operating in the emergency areas, outpatient consultation, imaging, laboratory and pharmacy.

Damages in the 3 hospitals that were fully disabled were the following:

- Hospital General Regional 36 "San Alejandro", Puebla (415 beds): damage to supporting walls and columns in the outpatient services, hospitalization, emergency, operating rooms and obstetric surgery buildings; subsidence and unevenness between the structures.

- The hospital had structural reinforcement at two different moments: first, for damages caused by an earthquake in 1993 and subsequently after the results of a PHS evaluation. The first reinforcement was carried out with steel diagonals with energy dissipators to achieve higher structural safety. The second reinforcement, was also based on a steel structure, but encasing columns with steel plates and diagonal structural beams, also of steel; investment was 244.4 million pesos and the works were still ongoing at the moment of the September earthquake; the reinforcement contributed to the building having a structurally acceptable response and not collapsing.

- Hospital General de Zona 7 Cuautla, Morelos (52 beds): partial damage in the emergency room, operating theaters, obstetric surgery area and major damage in the hospitalization area.

- Hospital General de Zona 32 Villa Coapa, Mexico City (205 beds): damage to load-bearing walls and finishes, and on main and emergency staircases.

The assessment results of the three hospitals that were disabled and shut down were reviewed (Table 3):

1. CNEDCPHS evaluation: it follows a strict protocol, it requires at least three trained evaluators, trained and certified by the Ministry of the Interior; they must belong to institutions other than that which is to be evaluated, as well as to different disciplines (doctors, engineers, architects, administrators, etc.); if the evaluation protocol is not complied with, the evaluation is canceled.

2. Civil Protection Comprehensive Information System Self-Assessment: in 2012, CNPC requested the different health institutions to have their medical units enter their information in an informatics platform where in an automated form the HSI was generated.

3. Self-assessment with the Real Estate Risk Identification Card (CIRI - Cédula de Identificación de Riesgos Inmobiliarios) based on the PAHO/ WHO CL: in 2016, the Mexican Institute of Social Security developed a platform as part of the Real Estate Risk Identification Program actions, where medical units entered their information, by means of which the HSI was obtained.

All three hospitals obtained an A HSI on the 2012 self-assessments, with higher scores than those obtained on the CNEDCPHS evaluations carried out by personnel specifically trained for that purpose; the self-assessment was carried out by hospital staff. This allows to consider the presence of bias at the moment the CL was applied; when the results of the CNEDCPHS assessments are compared with the self-assessments carried out in 2016 at the three hospitals, differences in the scores were appreciated again, although not so broad as in 2012.

The factors that can modify these results are diverse: experience of the staff for applying the CL, understanding of the concepts that are assessed, the form in which the CL is applied, since for the CNED$\mathrm{CPHS}$ evaluation, a strict protocol is followed, whereas self-assessments involve the government body and members of the Emergency Operations Committee. 


\section{Discussion}

The Mexican Institute of Social Security has adopted the PHS and is committed to mitigating the destructive effects of adverse phenomena and increase the safety of facilities, has made investments for reinforcement, has shut down hospitals when it has been necessary, has relocated them or built new buildings following the PHS guidelines; it has demolished a hospital located on a geological fault in Morelia, as well as a hospital in Mexico City with more than 50 years of age and with structural damage by the earthquake of March 20, 2012. ${ }^{12}$

The three hospitals that were disabled and shut down were built prior to 1980 when there were other construction codes, which were modified after the 1985 earthquake; this issue is evaluated in the $\mathrm{CL}$, in the structural safety section that specifies ground characteristics, type of subsoil, how it was built and hospital type, among others. In a systematic review on risk criteria for selection of the location site for a hospital, the main criteria were the cost and demand for services. ${ }^{13}$ Since their planning, new hospitals implement the PHS guidelines, where the importance of geographical location, type of soil, the threats hospitals will be exposed to and the use of technologies that are adequate to the different environmental conditions of the country and that, without detriment of medical services quality, support environmental sustainability, is established. This implies that, when designing a medical unit, factors such as fluid and solid residues reuse, waste minimization and awareness on the advantages of reducing the ecological impact are to be considered..$^{11,12}$

The damage a hospital can suffer in structural and non-structural aspects due to an earthquake are variable, from problems of finishes and detachment of false ceilings or walls, to total collapse of the building; structural behavior during the earthquake highly influences on non-structural components, especially those that are connected, such as vital lines.

Achour et al. ${ }^{14}$ summarize how structural and architectural damage are different and depend specifically on each situation, whereas damage to equipment and furniture is usually similar. These observations are complemented with those of the study by Kirsh et al. ${ }^{15}$ on the impact on hospital functionality after the 2010 earthquake in Chile, where none of the 7 studied hospitals collapsed; however, the main damage was the lack of external supplies such as water, energy and communications. None of the Mexican Institute of Social Security hospitals did collapse; however, there were damages that decreased their installed capacity.

When analyzing the data of the three hospitals' evaluations, the difference in the scores obtained on self-evaluations (carried out by hospital staff) stand out. Different factors can lead to underestimate or overestimate the scores awarded to each variable with regard to the CNEDCPHS assessment, where subjectivity is eliminated by the protocol that is followed and the independent evaluation staff. In the study by Ardalan et al., ${ }^{16} 421$ Iranian hospitals carried out their self-assessment in 2015, $80 \%$ were rated with medium safety and none with high safety; hospital emergency committees were responsible for entering the information to the platform developed for that purpose. In turn, Asefzadeh et al., ${ }^{17}$ when assessing two Iranian hospitals, observed a high level of safety; however, their results differ from those of other researchers, which is attributed to the data collection methods: oral interviews, written questionnaires, information collector experience, among others, which might coincide with the reasons for the differences in the three assessments of hospitals with damages we refer.

Functional organization vulnerability is a relevant issue because sometimes a hospital can be maintained physically and functionally fit; however, the lack of staff training for addressing an emergency or disaster can be its main weakness. In a study conducted in Tehran, Iran,,$^{18}$ one of the main vulnerabilities in the functional organization assessed by the CL was observed to be associated with the plans, guidelines, procedures, monitoring and evaluation. Chopin et al. ${ }^{19}$ in an investigation carried out after the 2007 earthquake in Peru, observed that a larger number of medical units that had an emergency response plan in place were able to maintain medical care than those without a plan $(p=0.043)$.

Another relevant aspect about emergency response plans is that they must have a multi-threat approach that considers the care of different types of injuries, as stated by Ushizawa et al. ${ }^{20}$ with regard to radiation exposure after the March 11, 2011 earthquake in Japan. In that regard, although in this analysis of damaged hospitals functional organization was not assessed separately, in the Mexican Institute of Social Security, protocols ${ }^{21}$ for care in emergencies and disasters are applied, which include evacuation of medical units with an emphasis on critical areas and plans for the care of a massive balance of victims, which allow the staff to immediately adapt the areas for the care of patients, discontinuation of non-priority services, establishment of triage areas and mechanisms for reference and counter-reference. 


\section{Conclusions}

September 2017 earthquakes of caused damage to 8 hospitals without any of them collapsing; however, three suffered damages that disabled them; in two, reinforcement works are being carried out and the other one will be demolished to build a new one.

Assessment under the PHS stricter protocol, independently of self-assessments, allows knowing the measures that must be taken to strengthen hospital safety. The costs generated by the investment on reinforcement have no comparison with what it means to safeguard life.

After the 2017 earthquakes, in Mexico we have the opportunity to continue developing a safe and resilient health sector.

\section{References}

1. Lista de Verificación de Hospitales Seguros. EE. UU.: Organización Panamericana de la Salud; 2008.

2. Conferencia Internacional sobre mitigación de desastres en instalaciones de salud. EE. UU.: Organización Panamericana de la Salud; 1997.

3. Hyogo Framework for Action 2005-2015: Building the Resilience of Nations and Communities to Disasters. EE. UU.: International Strategy for Disaster Reduction; 2005.

4. Sendai framework for disaster risk reduction 2015-2030. EE. UU.: Organización de las Naciones Unidas; 2015.

5. Instituto Mexicano del Seguro Social. Los rostros del IMSS. México: IMSS; 2017.

6. Organización Panamericana de la Salud. Lecciones aprendidas en América Latina en mitigación de desastres en instalaciones de la salud. Aspectos de costo-efectividad. EE. UU.: Organización Panamericana de la Salud/Organización Mundial de la Salud; 1996.

7. Cruz-Vega F, Elizondo-Argueta S, Hernández-Olivas IP, Méndez-Sánchez LM, Saavedra-Gómez JL. Hospital seguro. En: Pérez Castro y
Vázquez. Seguridad del paciente al alcance de todos. México: Academia Mexicana de Cirugía/Editorial Alfil; 2013.

8. Índice de seguridad hospitalaria: Guía del evaluador de hospitales seguros. EE. UU.: Organización Panamericana de la Salud; 2008.

9. Servicio Sismológico Nacional. Reporte especial: Sismo de Tehuantepec (2017-09-07 23:49 Mw 8.2). México: UNAM; 2017. Contents available at: http://www.ssn.unam.mx/sismicidad/reportes-especiales/2017/SSNMX_rep_esp_20170907_Tehuantepec_M82.pdf

10. Servicio Sismológico Nacional. Reporte especial: Sismo del día 19 de Septiembre de 2017, Puebla-Morelos (M 7.1). México: UNAM; 2017. Contents available at : http://www.ssn.unam.mx/sismicidad/reportes-especiales/2017/SSNMX_rep_esp_20170919_Puebla-Morelos_M71.pdf

11. Instituto Mexicano del Seguro Social. El seguro de México. Los primeros 75 años. México: Algarabía; 2017.

12. Instituto Mexicano del Seguro Social. Informe de labores y programa de actividades 2016-2017. México: Instituto Mexicano del Seguro Social; 2017.

13. Moradian MJ, Ardalan A, Nejati A, Boloorani AD, Akbarisari A, Rastegarfar B. Risk criteria in hospital site selection: a sistematic review. PLoS Curr. 2017;9:pii.

14. Achour N, Miyajima M, Kitaura M, Price A. Earthquake induced structural and non-structural damage in hospitals. Earthquake Spectra. 2011,27(3): 617-634.

15. Kirsh TD, Mitrani-Reiser J, Bissell R, Sauer LM, Mahoney M, Holmes WT, et al. Impact on hospital earthquake functions following the 2010 Chilean earthquake. Disaster Med Public Health Prep. 2010;4(2):122-128.

16. Ardalan A, Kandi Keleh M, Saberinia A, Khorasani-Zavareh D, Khankeh H, Miadfar J, et al. (2016) 2015 estimation of hospitals safety from disasters in I.R.Iran: the results from the assessment of 421 hospitals. PLoS ONE. 2016;11(9):e0161542.

17. Asefzadeh S, Varyani AS, Gholami S. Disaster risk assessment in educational hospitals of Qazvin based on WHO pattern in 2015. Electronic Physician. 2016;8(1):1770-1775.

18. Ahmadi B, Foroushani AR, Tanha N, Abad AM, Asadi H. Study of functional vulnerability status of Tehran Hospitals in dealing with natural disasters. Electronic Physician. 2016;8(11):3198-3204.

19. Chapin E, Daniels A, Elias R, Aspilcueta D, Doocy S. Impact of the 2007 Ica earthquake on health facilities and health service provision in southern Peru. Prehosp Disaster Med. 2009;24(4):326-332.

20. Ushizawa H, Foxwell AR, Bice S, Matsui T, Ueki Y, Tosaka N, et al. Needs for disaster medicine: lessons from the field of the Great East Japan Earthquake. Western Pac Surveill Response J. 2013;4(1):51-55.

21. Echevarría-Zuno S, Cruz-Vega F, Elizondo-Argueta S, Martínez-Valdés E, Franco-Bey R, Méndez-Sánchez LM. Atención en emergencias y desastres en las unidades de terapia intensiva del Instituto Mexicano del Seguro Social: triage y evacuación. Cir Cir. 2013;81(3):246-255. 